\section{RMD Open}

Rheumatic \&

Musculoskeletal Diseases

\title{
Can power Doppler ultrasound of the entheses help in classifying recent axial spondyloarthritis? Data from the DESIR cohort
}

To cite: Poulain C, D'Agostino MA, Thibault S, et al. Can power Doppler ultrasound of the entheses help in classifying recent axial spondyloarthritis? Data from the DESIR cohort. RMD Open 2018;4:e000686. doi:10.1136/ rmdopen-2018-000686

- Prepublication history for this paper is available online. To view these files, please visit the journal online (http://dx.doi. org/10.1136/rmdopen-2018000686).

Dr Alain Rahmouni died on 25 January 2018

Received 22 March 2018 Revised 19 June 2018 Accepted 21 June 2018

Check for updates

(C) Author(s) (or their employer(s)) 2018. Re-use permitted under CC BY-NC. No commercial re-use. See rights and permissions. Published by BMJ.

For numbered affiliations see end of article.

Correspondence to Pascal Claudepierre; pascal.claudepierre@aphp.fr

\section{ABSTRACT}

Early diagnosis of axial spondyloarthritis (axSpA) remains a challenge due to the lack of specificity of clinical symptoms and variable prevalence of axial imaging findings permitting a definite diagnosis. Power Doppler ultrasonography (PDUS) of the entheses has demonstrated to be a potential useful tool for the classification and diagnostic management of early SpA independently of the phenotype.

Objectives To assess the classification value (sensitivity and specificity) of PDUS-defined enthesitis for identifying patients fulfilling Assessment of SpondyloArthritis international Society (ASAS) classification criteria for axSpA (ASAS+) in patients with recent inflammatory back pain (IBP) (the DESIR (DEvenir des Spondylarthropathies Indifférenciées Récentes) cohort).

Methods Baseline PDUS was performed at eight entheseal sites, and PDUS enthesitis was defined by the presence of vascularisation at entheseal insertion.

Results 402 patients from the DESIR cohort underwent a PDUS evaluation. PDUS enthesitis was detected in 58 (14.4\%) patients of whom $40(14.2 \%)$ belonged to the ASAS+ patients and $18(17 \%)$ to the ASAS- patients. The sensitivity of PDUS enthesitis was $13.9 \%$ and the specificity was $83.5 \%$, with a positive predictive value of $69 \%$ and $26.8 \%$ of negative predictive value for meeting ASAS criteria for axSpA. Of the 18 ASAS- patients with positive PDUS, 59\% fulfilled Amor's criteria, 88\% European Spondyloarthropathy Study Group criteria and 59\% both. Conclusions In a cohort of patients with recent IBP, the prevalence of PDUS enthesitis was low (14.4\%); however, its specificity for classifying patients as axSpA according to ASAS criteria was high (83.5\%). PDUS enthesitis might be of additional value for classifying as patients with axSpA IBP who do not fulfil ASAS criteria.

\section{INTRODUCTION}

Early diagnosis of axial spondyloarthritis (axSpA) remains a challenge, as the radiographic sacroiliitis that allows a definite diagnosis of ankylosing spondylitis takes 5-10 years to develop. 1 The classification criteria developed recently by the Assessment of

\section{Key messages}

What is already known about this subject?

- Power Doppler ultrasonography (PDUS) of the entheses has demonstrated to be a potential useful tool for the classification and diagnostic management of spondyloarthritis $(\mathrm{SpA})$.

What does this study add?

- In a cohort of patients with recent inflammatory back pain (IBP) highly suggestive of axial $\mathrm{SpA}$ the use of PDUS of entheses may help in classifying those patients who do not fulfil Assessment of SpondyloArthritis international Society (ASAS) classification criteria for axial SpA but fulfil other classification criteria for $\mathrm{SpA}$.

How might this impact on clinical practice?

- PDUS of the entheses could be performed in clinical practice to help classifying as patients with axial $\mathrm{SpA}$ patients with recent IBP suggestive of SpA who do not fulfil ASAS classification criteria.

SpondyloArthritis international Society (ASAS) permit to accelerate the classification of axSpA by allowing the possibility to objective axial involvement either by using MRI in case of the absence of radiographic sacroiliac joints (SIJ) involvement or through a 'clinical arm' that identifies axSpA based on the presence of HLA-B27 plus at least two other clinical features, even in the absence of definite SIJ abnormalities by radiography or MRI. ${ }^{2}{ }^{3}$ The accuracy of ASAS criteria for establishing an early diagnosis of axSpA has been studied, ${ }^{4-6}$ underlying the role of SIJ MRI inflammation; however, few data are available about the potential contribution of abnormal imaging findings other than SIJ inflammation. ${ }^{6}{ }^{7}$ Such findings may include structural SIJ MRI abnormalities, structural spinal MRI abnormalities 
and inflammatory spinal MRI abnormalities. In addition, several studies suggest that power Doppler ultrasonography (PDUS) of the entheses may assist in the early diagnosis and follow-up of SpA. ${ }^{8-10}$ According to a consensus recently developed by the Outcome Measure in Rheumatology Clinical Trials (OMERACT) Ultrasound Working Group, SpA-related enthesitis can be defined by the presence of several elementary components including hypoechogenicity, thickening of the tendon insertion, calcifications, enthesophytes, erosions and Doppler activity within $2 \mathrm{~mm}$ from the bony cortex. ${ }^{11}$ Among these components, Doppler signal seems to be the most specific and most representative ultrasound sign of active entheseal inflammation in SpA. ${ }^{12-14}$ Few studies have evaluated the diagnostic value of the PDUS evaluation of entheses in a population likely to benefit from this imaging tool such as patients with recent inflammatory back pain (IBP) suggestive of axSpA. ${ }^{14}$ The prevalence of the various PDUS entheseal abnormalities in a cohort of patients with recent IBP suggestive of axSpA (DESIR (DEvenir des Spondylarthropathies Indifférenciées Récentes) cohort) has been recently reported. ${ }^{15}$

The main objective of this study was therefore to assess the sensitivity and specificity of PDUS-defined enthesitis for identifying patients fulfilling ASAS classification criteria for axSpA, in the DESIR cohort of patients with recent IBP.

\section{PATIENTS AND METHODS}

\section{Study design}

We performed a cross-sectional analysis of baseline findings from the prospective longitudinal DESIR cohort (\#NCT01648907) of 708 patients with recent-onset IBP ( $<3$ years) and a strong suspicion of axSpA. These patients were recruited in 25 rheumatology centres in France between December 2007 and April 2010. ${ }^{16} 17$

Patient age at baseline ranged from 18 to 50 years. The IBP affected the thoracic or lumbar spine or the buttock area and fulfilled either Calin criteria (4/5) or Berlin criteria $(2 / 4)$. The rheumatologist rated the manifestations $\geq 5$ on a 10-point scale where 0 indicated no suspicion of SpA and 10 a very strong suspicion of SpA. A detailed description of the study centres, cohort organisation, protocol and case-report form is available online http://www.lacohortedesir.fr/desir-in-english/put. The present study is reported according to the Strengthening the Reporting of Observational Studies in Epidemiology statement. ${ }^{18}$

\section{Data collection}

The following characteristics were collected at baseline: sociodemographic data, history of the disease, main rheumatic symptoms (past or current enthesitis, dactylitis, arthralgia, arthritis) and extrarheumatic symptoms (past or current uveitis, psoriasis, inflammatory bowel disease (IBD)), environmental factors (tobacco or alcohol consumption, yes/no), biological parameters (C reactive protein (CRP) level, presence/absence of
HLA-B27), treatments (use of non-steroidal anti-inflammatory drugs (NSAIDs), responsiveness to NSAIDs, ASAS NSAID score, use of disease-modifying antirheumatic drugs (DMARDs), use of analgesics), disease activity and function scores (patient global assessment, Bath Ankylosing Spondylitis Disease Activity Index (BASDAI), Bath Ankylosing Spondylitis Functional Index (BASFI), ASDAS-crp), physical findings (enthesitis index, synovitis index) and spondyloarthritis classification criteria (Amor's criteria, European Spondyloarthropathy Study Group (ESSG) criteria, ASAS criteria for axSpA). Baseline imaging data obtained using a standardised procedure were also collected: pelvic and spinal radiographs, MRI of the SIJs and spine and PDUS of predefined entheses. ${ }^{16}$

\section{Power Doppler ultrasonography (PDUS) procedure and PDUS-} defined enthesitis

PDUS of the entheses was performed in 14 out of the 25 centres of the cohort. These 14 centres recruited 402 patients into DESIR, who were evaluated for the actual research question.

PDUS was performed by a rheumatologist or radiologist expert in PDUS blinded to clinical data according to a standardised procedure. Rheumatologists were specifically trained to PDUS of the entheses by the person in charge of the PDUS protocol of the DESIR cohort (MADA). In addition, all rheumatologists had access to a set of images showing different degrees of enthesis inflammation as comparator. No reliability exercise was performed since each sonographer was taught by the same person and compared with her. Different machines were used but all were considered equivalent in term of quality and parameters for B mode and Doppler. In grey-scale (or B mode), a high frequency linear probe was used (around 10-15 $\mathrm{MHz}$ ). The power Doppler settings were standardised using a pulse repetition frequency around $500-750 \mathrm{~Hz}$ or as set by the ultrasonography machine to allow a study of slow flow. The following four entheseal insertions were examined bilaterally in both planes: Achilles tendon, proximal and distal insertion of the patellar ligament and common extensor tendon on the lateral epicondyle of the elbow. Morphological and structural abnormalities were sought in $\mathrm{B}$ mode and vascularisation at bony insertions was assessed by power Doppler.

PDUS enthesitis was defined according to the OMERACT definition, ${ }^{11}$ PDUS active enthesitis was restrained to positive Doppler at bony insertion, in order to be more specific of SpA enthesitis. ${ }^{12-14}$ Figures 1-3 illustrate which type of lesions has been retained for the PDUS enthesitis diagnosis. On the day of PDUS, independent investigators performed physical examinations, following a standardised protocol (http://www.lacohortedesir.fr/desir-in-english/put) to assess past pain and local provoked pain at the eight entheseal sites selected for PDUS. The Ultrasound equipments that have been used were the following: Esaote My Lab 70 (37\%), Esaote My Lab 60 (24.3\%), Esaote technos MPX (7\%), General Electrics Voluson 750 (15.3\%), Siemens Antares (16.4\%). 


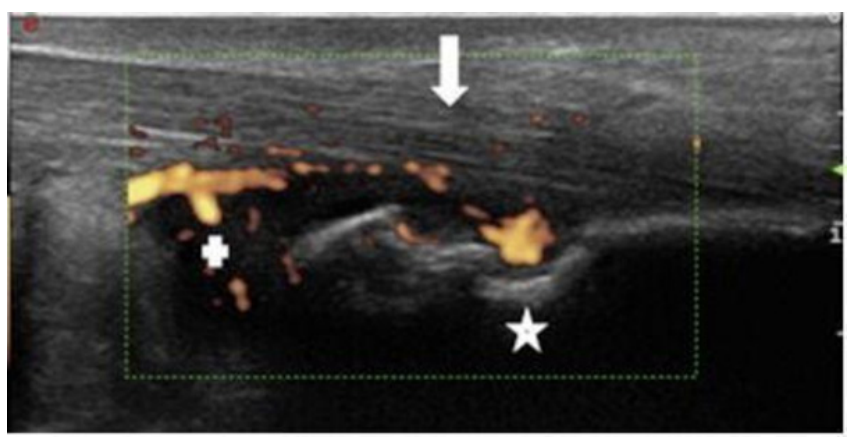

Figure 1 PDUS scan of an Achilles' enthesis complex showing enthesitis (erosion of calcaneum with Doppler signal (star)), tendinitis (arrow) and bursitis (+). PDUS, power Doppler ultrasonography.

The technical parameters of the devices were the following: Linear probe 10-14 MHz, Doppler frequency 14.1 MHz, PRF $500 \mathrm{~Hz}$.

\section{Radiographs and MRI}

Standard radiographs of the cervical spine, lumbar spine and pelvis were obtained and interpreted locally according to a standardised procedure (lacohortedesir. com). Radiographs of each SIJ were scored on a variant of New York classification criteria a four-point scale (0, normal; 1, doubtful; 2, obviously abnormal and 3, fused), previously described. ${ }^{19}$ Radiographic sacroiliitis was defined as a score of 2 or 3 for at least one SIJ. The modified Stoke Ankylosing Spondylitis Spine Score ${ }^{20}$ was used to assess structural changes at the cervical and lumbar spine. MRI scans of the SIJ, upper spine (C2 to T10) and lower spine (T8 to S1) were performed using T1-weighted spin echo and short-tau inversion recovery T2-weighted sequences. Inflammatory changes were defined as bone oedema in or adjacent to the SIJ or as bone oedema at one or more vertebral corners or entire vertebrae with or without disc involvement. Each MRI abnormality was scored on a 3-point scale (0, normal; 1 , doubtful and 2, abnormal). For this analysis, MRI was considered abnormal only if scored 2.

\section{Statistical analysis}

Our primary objective was to evaluate the sensitivity and specificity of PDUS-defined enthesitis (at one or more

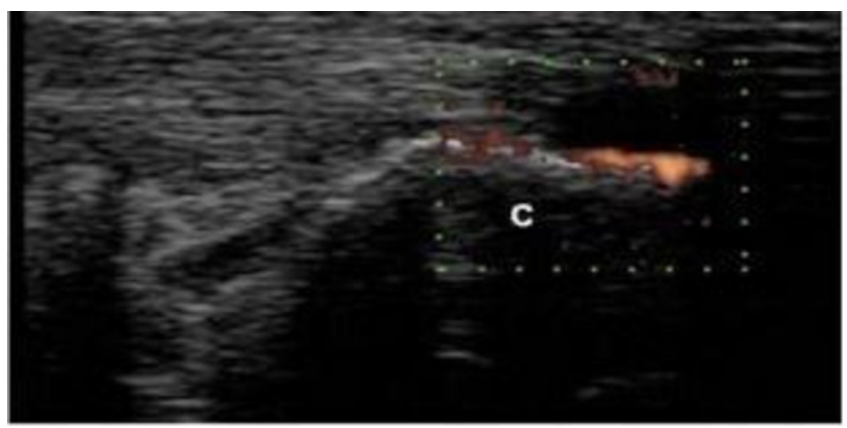

Figure 2 Achilles enthesitis with Doppler signal within 2 $\mathrm{mm}$ from bony cortex.

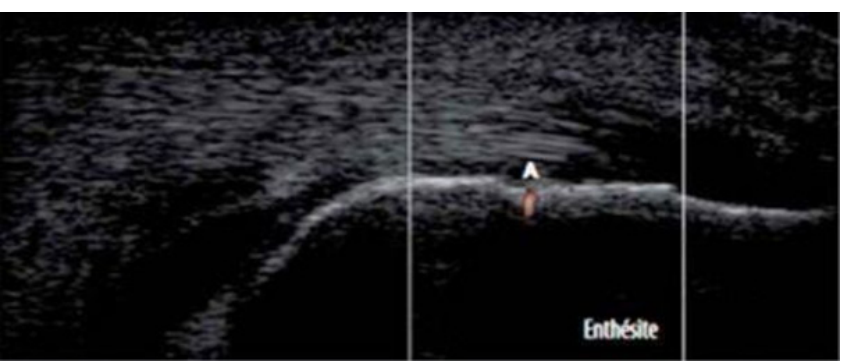

Figure 3 Smallest detectable Doppler signal considered for the diagnosis of PDUS enthesitis in the DESIR cohort. DESIR, DEvenir des Spondylarthropathies Indifférenciées Récentes; PDUS, power Doppler ultrasonography.

sites) using the axSpA ASAS classification criteria as reference standard. We estimated the sample size needed according to the best compromise between sensitivity and specificity of PDUS. Obtaining $>0.8$ sensitivity with a relative error of $5 \%$ and an absolute error of $5 \%$ required 246 patients fulfilling axSpA ASAS criteria (ASAS+); assuming $10 \%$ of uninterpretable data, the number was 274. Obtaining $>0.7$ specificity with $5 \%$ relative error and $10 \%$ absolute error required 81 patients who did not fulfil axSpA ASAS criteria (ASAS-); assuming 10\% of uninterpretable data, the number was 90 . Thus, 364 patients were needed, with an ASAS+/ASAS- ratio of 3/1.

Categorical variables were described as $\mathrm{n}(\%)$ and quantitative variables as mean (SD) or median (IQR). ANOVA or the Kruskal-Wallis test, as appropriate, was chosen for comparisons. For quantitative variables, we used the Newman-Keuls method to analyse the subgroups when the global test was significant. For categorical variables, we used the $\chi^{2}$ test to compare one level versus the other levels. When appropriate, for subgroups analysis, Bonferroni's correction for multiple comparisons was performed. Concordance was estimated, and the 95\% CI computed using Cohen's kappa coefficient $(\kappa)$ and analysing the structures of the margins. A centre effect was sought by performing a homogeneity test on $\kappa$ values from each centre. If necessary, a Cicchetti weighted $\kappa$ was estimated according to Fleiss and Cicchetti. ${ }^{21}{ }^{22}$ Final $\mathrm{p}<0.05$ were considered significant. SAS software V.9.3 (SAS Institute, Cary, North Carolina, USA) and R software (https://www.r-project.org/) were used.

\section{RESULTS}

\section{Group comparisons}

Of the 708 patients of the DESIR cohort, 402 patients underwent PDUS. When comparing patients with and without PDUS evaluation, after Bonferroni's correction, the only statistically significant difference was a higher prevalence of radiographic sacroiliitis in the group with PDUS evaluation (31.7\% vs $20.5 \%, \mathrm{p}=0.001$ ) (other data not shown).

Of those 402 patients who underwent PDUS, 58 (14.4\%) had enthesitis defined as any vascularisation (power Doppler signal) at the bony insertion of the tendon, within $2 \mathrm{~mm}$ from the bony cortex, at one or 
Table 1 Baseline characteristics of the 402 DESIR patients who underwent PDUS of the entheses (eightsites) according to the presence/absence of PDUS enthesitis*

\begin{tabular}{|c|c|c|c|}
\hline & $\begin{array}{l}\text { PDUS enthesitis* } \\
\text { PDUS+ } \\
\text { (n=58) }\end{array}$ & $\begin{array}{l}\text { No PDUS enthesitis* } \\
\text { PDUS- } \\
\text { (n=327) }\end{array}$ & $\mathbf{P}$ value \\
\hline Female gender & $27(46.6 \%)$ & $172(52.6 \%)$ & 0.476 \\
\hline Age (years) & $35.5(28.7-44)$ & $32.91(26.4-39.1)$ & 0.036 \\
\hline Disease duration (years) & $1.43(0.73-2.17)$ & $1.45(0.72-2.33)$ & 0.748 \\
\hline Smoker & $16(27.6 \%)$ & $118(36.1 \%)$ & 0.288 \\
\hline Alcohol use & $10(17.2 \%)$ & $53(16.3 \%)$ & 0.654 \\
\hline \multicolumn{4}{|l|}{ History of: } \\
\hline Enthesitis & $43(74.1 \%)$ & $156(47.7 \%)$ & $<0.001$ \\
\hline Dactylitis & $7(12.1 \%)$ & $41(12.5 \%)$ & 1.000 \\
\hline Arthralgia & $43(74.1 \%)$ & $179(54.7 \%)$ & 0.006 \\
\hline Arthritis & $18(42.9 \%)$ & $55(30.9 \%)$ & 0.149 \\
\hline EAS $\ddagger$ & $26(44.8 \%)$ & $88(26.9 \%)$ & 0.008 \\
\hline HLA-B27+ & $31(53.6 \%)$ & $192(58.7 \%)$ & 0.473 \\
\hline $\mathrm{CRP}>6 \mathrm{mg} / \mathrm{L}$ & $14(24.6 \%)$ & $88(27.8 \%)$ & 0.747 \\
\hline BASDAI (0-100) & $53(30-63)$ & $43(28-58)$ & 0.033 \\
\hline BASFI (0-100) & $32(15-56)$ & $22(11-46)$ & 0.062 \\
\hline PGA & $4.5(3-6)$ & $4(2-6)$ & 0.132 \\
\hline ASDAS-crp & $2.84(2.19-3.79)$ & $2.55(1.87-3.28)$ & 0.039 \\
\hline Enthesitis index & $2(0-5)$ & $2(0-4)$ & 0.241 \\
\hline Synovitis index $\geq 1$ & $7(12.1 \%)$ & $18(5.5 \%)$ & 0.079 \\
\hline BASMI & $2.5(1.6-3.2)$ & $2.2(1.6-2.8)$ & 0.124 \\
\hline \multicolumn{4}{|l|}{ Past§ or current treatments: } \\
\hline Analgesics & $40(68.9 \%)$ & $206(63.0 \%)$ & 0.459 \\
\hline DMARD & $11(18.9 \%)$ & $33(10.1 \%)$ & 0.070 \\
\hline NSAID responsiveness & $46(80.7 \%)$ & $263(80.9 \%)$ & 1.000 \\
\hline ASAS NSAID score & $29.2(6.99-64.72)$ & 40.9 (14.83-74.66) & 0.077 \\
\hline Radiographic sacroiliitis & $21(36.2 \%)$ & $99(30.8 \%)$ & 0.444 \\
\hline MRI SIJ inflammation & $21(36.8 \%)$ & $120(37.2 \%)$ & 1.000 \\
\hline MRI spinal inflammation & $11(19.3 \%)$ & $71(22 \%)$ & 0.729 \\
\hline mSASSS Mean (SD) & $1.41(3.7)$ & $0.49(1.8)$ & 0.082 \\
\hline Amor+ & $47(82.5 \%)$ & $263(82.7 \%)$ & 1.000 \\
\hline ESSG+ & $53(91.4 \%)$ & $261(79.8 \%)$ & 0.042 \\
\hline ASAS Axial & 40 (67\%) & $234(72.7 \%)$ & 0.633 \\
\hline
\end{tabular}

Categorical data are $\mathrm{n}(\%)$. Continuous variables are expressed as Median (IQR) or otherwise indicated.

*PDUS enthesitis was defined as vascularisation at one or more of eight predefined enthesis sites. Vascularisation was defined as a power Doppler signal at the bony insertion of the tendon, within $2 \mathrm{~mm}$ from the bony cortex. The eight entheseal sites were the Achilles tendon, proximal and distal insertions of the patellar ligament and lateral epicondyle on both sides.

†Results are expressed before Bonferroni's correction.

fEAS: extra-articular symptoms including psoriasis, uveitis and inflammatory bowel disease. 17 patients without PDUS enthesitis were excluded from the analysis due to missing data.

§In the last 6 months.

ASAS, Assessment of SpondyloArthritis international Society; ASDAS-crp, Ankylosing Spondylitis Disease Activity Score computed using the C reactive protein level; BASDAI, Bath Ankylosing Spondylitis Disease Activity Index; BASFI, Bath Ankylosing Spondylitis Functional Index; BASMI, Bath Ankylosing Spondylitis Metrology Index; CRP, C reactive protein; DESIR, DEvenir des Spondylarthropathies Indifférenciées Récentes; DMARD, disease-modifying antirheumatic drug; EAS, extra-articular symptoms; ESSG, European Spondyloarthropathy Study Group; m, missing; mSASSS, modified Stoke Ankylosing Spondylitis Spinal Score; PDUS, power Doppler ultrasonography; PGA, physician global assessment; SIJ, sacroiliac joint; y, years. 
Table 2 Sensitivity, specificity, PPV and NPV of enthesitis by PDUS for meeting ASAS classification criteria for axial spondyloarthritis, in the DESIR cohort

\begin{tabular}{|c|c|c|c|c|c|}
\hline $\begin{array}{l}\text { PDUS performed } \\
\mathrm{N}=402\end{array}$ & $\begin{array}{l}\text { PDUS enthesitis } \\
\mathrm{N}(\%)\end{array}$ & $\begin{array}{l}\text { Sensitivity } \\
\text { (IC 95\%) }\end{array}$ & $\begin{array}{l}\text { Specificity } \\
\text { (IC 95\%) }\end{array}$ & $\begin{array}{l}\text { PPV } \\
\text { (IC 95\%) }\end{array}$ & $\begin{array}{l}\text { NPV } \\
\text { (IC 95\%) }\end{array}$ \\
\hline PDUS enthesitis at any site & $\begin{array}{l}58 \\
(14.4 \%)\end{array}$ & $\begin{array}{l}13.9 \% \\
(9.9 \text { to } 17.9)\end{array}$ & $\begin{array}{l}83.5 \% \\
\text { (76.5 to } 90.4)\end{array}$ & $\begin{array}{l}69 \% \\
\text { (57 to } 80.9)\end{array}$ & $\begin{array}{l}26.8 \% \\
\text { (22.1 to } 31.5)\end{array}$ \\
\hline Achille's PDUS enthesitis & $\begin{array}{l}15 \\
(3.7 \%)\end{array}$ & $\begin{array}{l}4 \% \\
(1.8 \text { to } 6.4)\end{array}$ & $\begin{array}{l}97 \% \\
\text { (94.2 to } 100)\end{array}$ & $\begin{array}{l}80 \% \\
\text { (59.7 to } 100)\end{array}$ & $\begin{array}{l}28 \% \\
\text { (23.2 to } 32.2)\end{array}$ \\
\hline $\begin{array}{l}\text { Patellar ligaments PDUS } \\
\text { enthesitis }\end{array}$ & $\begin{array}{l}36 \\
(9 \%)\end{array}$ & $\begin{array}{l}8 \% \\
(5.1 \text { to } 11.5)\end{array}$ & $\begin{array}{l}89 \% \\
\text { (83.1 to } 94.8)\end{array}$ & $\begin{array}{l}67 \% \\
\text { (51.2 to } 82.1)\end{array}$ & $\begin{array}{l}27 \% \\
(22.2 \text { to } 31.4)\end{array}$ \\
\hline $\begin{array}{l}\text { Lateral epicondyle PDUS } \\
\text { enthesitis }\end{array}$ & $\begin{array}{l}20 \\
(5 \%)\end{array}$ & $\begin{array}{l}5 \% \\
(2.4 \text { to } 7.3)\end{array}$ & $\begin{array}{l}94 \% \\
\text { (90.2 to } 98.7)\end{array}$ & $\begin{array}{l}70 \% \\
(49.9 \text { to } 90.1)\end{array}$ & $\begin{array}{l}27 \% \\
\text { (22.8 to } 31.8)\end{array}$ \\
\hline
\end{tabular}

The sensitivity and specificity of PDUS-defined enthesitis were calculated on the 402 patients who underwent PDUS, using classification as axial spondyloarthritis according to the ASAS criteria as the reference standard ( $n=288$ patients met these criteria).

ASAS, Assessment of SpondyloArthritis international Society; DESIR, DEvenir des Spondylarthropathies Indifférenciées Récentes; NPV, negative predictive value; PDUS, power Doppler ultrasonography; PPV, positive predictive value.

more sites. No statistically significant centre effect was found (data not shown). Table 1 compares the groups with and without PDUS-defined enthesitis (PDUS+ and PDUS-). After Bonferroni's correction, the only significant difference was a higher prevalence of a past history of enthesitis in the PDUS+ group $(74.1 \%$ vs $47.7 \%$, $\mathrm{p}<0.001)$.

\section{Sensitivity and specificity of enthesitis by power Doppler ultrasonography (PDUS)}

In the overall population, using ASAS criteria for axSpA as the reference standard, the sensitivity and specificity of PDUS-defined enthesitis for classifying patients as having axSpA were $13.9 \%$ and $83.5 \%$, respectively (table 2 ).
Table 2 also reports the accuracy of PDUS-defined enthesitis at each site. Among the 58 patients with PDUS-defined enthesitis, 36 (62\%) had enthesitis of the patellar ligaments, $20(34 \%)$ of the lateral epicondyle and $15(26 \%)$ of the Achilles tendon. The sensitivity and specificity of PDUS-defined enthesitis were similar when using the ESSG criteria or Amor or modified Amor's criteria (sacroiliitis by radiography or STIR MRI or both) or a rheumatologist's suspicion of axSpA score $\geq 8 / 10$ as the reference standard (table 3 ).

PDUS enthesitis was defined as vascularisation at one or more of eight predefined enthesis sites. Vascularisation was defined as a power Doppler signal at the

Table 3 Sensitivity, specificity, PPV and NPV of PDUS-defined enthesitis at any site for meeting various classification criteria for spondyloarthritis, in the DESIR cohort

\begin{tabular}{|c|c|c|c|c|}
\hline Classification criteria & $\begin{array}{l}\text { Sensitivity } \\
\text { (IC 95\%) }\end{array}$ & $\begin{array}{l}\text { Specificity } \\
\text { (IC } 95 \%)\end{array}$ & $\begin{array}{l}\text { PPV } \\
\text { (IC 95\%) }\end{array}$ & $\begin{array}{l}\text { NPV } \\
\text { (IC 95\%) }\end{array}$ \\
\hline Axial ASAS & $\begin{array}{l}13.9 \% \\
(9.9 \text { to } 17.9)\end{array}$ & $\begin{array}{l}83.5 \% \\
(76.5 \text { to } 90.4)\end{array}$ & $\begin{array}{l}69.0 \% \\
(57 \text { to } 80.9)\end{array}$ & $\begin{array}{l}26.8 \% \\
(22.1 \text { to } 31.5)\end{array}$ \\
\hline ESSG & $\begin{array}{l}16.1 \% \\
(12.1 \text { to } 20.1)\end{array}$ & $\begin{array}{l}93.1 \% \\
(87.3 \text { to } 98.9)\end{array}$ & $\begin{array}{l}91.4 \% \\
(84.1 \text { to } 98.6)\end{array}$ & $\begin{array}{l}19.8 \% \\
(15.5 \text { to } 24)\end{array}$ \\
\hline Modified Amor ${ }^{*}$ & $\begin{array}{l}14.6 \% \\
(10.7 \text { to } 18.3)\end{array}$ & $\begin{array}{l}86.7 \% \\
(78 \text { to } 95.2)\end{array}$ & $\begin{array}{l}85.7 \% \\
(76.5 \text { to } 94.9)\end{array}$ & $\begin{array}{l}15.6 \% \\
(11.7 \text { to } 19.4)\end{array}$ \\
\hline Amor & $\begin{array}{l}14.5 \% \\
(10.7 \text { to } 18.3)\end{array}$ & $\begin{array}{l}85.3 \% \\
(76.9 \text { to } 93.7)\end{array}$ & $\begin{array}{l}82.4 \% \\
(72.6 \text { to } 92.3)\end{array}$ & $\begin{array}{l}17.3 \% \\
(13.7 \text { to } 21.7)\end{array}$ \\
\hline Rheumatologist's confidence score $\geq 8 / 10$ & $\begin{array}{l}16.7 \% \\
(11.4 \text { to } 21.9)\end{array}$ & $\begin{array}{l}87.6 \% \\
(83.2 \text { to } 92.1)\end{array}$ & $\begin{array}{l}55.2 \% \\
(42.3 \text { to } 68)\end{array}$ & $\begin{array}{l}53.5 \% \\
(48.2 \text { to } 58.7)\end{array}$ \\
\hline $\begin{array}{l}\text { Amor or modified Amor or ESSG or } \\
\text { rheumatologist's confidence score } \geq 8 / 10\end{array}$ & $\begin{array}{l}14.9 \% \\
(11.3 \text { to } 18.4)\end{array}$ & $\begin{array}{l}94.7 \% \\
(84.7 \text { to } 100)\end{array}$ & $\begin{array}{l}98.3 \% \\
\text { (94.9 to } 100)\end{array}$ & $\begin{array}{l}5.2 \% \\
(2.8 \text { to } 7.6)\end{array}$ \\
\hline $\begin{array}{l}\text { Amor and modified Amor and ESSG and } \\
\text { rheumatologist's confidence score } \geq 8 / 10 \text { and } \\
\text { ASAS }\end{array}$ & $\begin{array}{l}16.3 \% \\
(10.2 \text { to } 22.4)\end{array}$ & $\begin{array}{l}86.6 \% \\
(82.4 \text { to } 90.7)\end{array}$ & $\begin{array}{l}39.7 \% \\
(27.1 \text { to } 52.2)\end{array}$ & $\begin{array}{l}65.7 \% \\
(60.7 \text { to } 70.7)\end{array}$ \\
\hline
\end{tabular}

*In the modified Amor criteria, sacroiliitis is defined as radiographic sacroiliitis or sacroiliac joint inflammation by MRI.

ASAS, Assessment of SpondyloArthritis international Society; DESIR, DEvenir des Spondylarthropathies Indifférenciées Récentes; ESSG,

European Spondyloarthropathy Study Group; NPV, negative predictive value; PDUS, power Doppler ultrasonography; PPV, positive

predictive value. 
Table 4 Enthesitis by PDUS according to ASAS criteriafor axial spondyloarthritis

\begin{tabular}{|c|c|c|c|c|}
\hline \multirow{3}{*}{$\begin{array}{l}\text { PDUS examination } \\
\mathrm{N}=402\end{array}$} & \multicolumn{2}{|c|}{ ASAS $+\mathrm{N}=288$} & \multicolumn{2}{|c|}{ ASAS- $N=109$} \\
\hline & $\begin{array}{l}\text { Radiographic/MRI } \\
\text { sacroiliitis } \mathrm{N}=189\end{array}$ & $\begin{array}{l}\text { HLA-B27 and } 2 \text { other } \\
\text { clinical features } \mathrm{N}=96\end{array}$ & $\mathrm{CRP}<6 \mathrm{mg} / \mathrm{L} \mathrm{N}=19$ & $\mathrm{CRP}>6 \mathrm{mg} / \mathrm{L} \mathrm{N}=87$ \\
\hline & \multicolumn{2}{|c|}{$\mathrm{MD}=3$} & $\mathrm{MD}=0$ & $M D=3$ \\
\hline \multirow{3}{*}{$\begin{array}{l}\text { PDUS enthesitis } N=58 \\
(58 / 402=14.4 \%)\end{array}$} & \multicolumn{2}{|c|}{$A S A S+N=40$} & \multicolumn{2}{|c|}{ ASAS-N=18 } \\
\hline & $\begin{array}{l}\text { Radiographic/MRI } \\
\text { sacroiliitis } \mathrm{N}=29 \\
(29 / 186=10.1 \%)\end{array}$ & $\begin{array}{l}\text { HLA-B27 and } 2 \text { other } \\
\text { clinical features } \mathrm{N}=10 \\
(10 / 95=10.5 \%)\end{array}$ & $\begin{array}{l}\text { CRP }<6 \mathrm{mg} / \mathrm{L} N=3 \\
(3 / 19=15.8 \%)\end{array}$ & $\begin{array}{l}\mathrm{CRP}>6 \mathrm{mg} / \mathrm{L} \mathrm{N}=14 \\
(14 / 87=16.1 \%)\end{array}$ \\
\hline & $M D=3$ & $M D=1$ & $M D=0$ & $M D=1$ \\
\hline
\end{tabular}

ASAS, Assessment of SpondyloArthritis international Society; CRP, C reactive protein; MD, missing data; PDUS, power Doppler ultrasonography.

bony insertion of the tendon, within $2 \mathrm{~mm}$ from the bony cortex. The eight entheseal sites were the Achilles tendon, proximal and distal insertions of the patellar ligament and lateral epicondyle, on both sides. The data are $\mathrm{n}(\%)$.

\section{Enthesitis by power Doppler ultrasonography (PDUS) and ASAS criteria}

As shown in table 4, the prevalence of PDUS-defined enthesitis was $14.2 \%(40 / 281)$ in the ASAS+ group and $17 \%(18 / 106)$ in the ASAS- group $(p=0.562)$. The prevalence of PDUS-defined enthesitis was neither significantly different between patients meeting the imaging arm (29 patients out of 186, 10.1\%) vs the clinical arm (10 patients out of $95,10.5 \%$ ) of the ASAS criteria set. Within the ASAS- group, no significant differences were noted between patients with and without CRP elevation.

Table 5 lists the main characteristics of the 18 PDUS+ ASAS- patients. Amor's criteria were assessable in 17 patients, of whom $11(65 \%)$ met these criteria; 16/18 $(89 \%)$ patients met ESSG criteria and 11/17 (65\%) met both criteria sets.

Mean age was 38.2 years, with a mean disease duration of 1.8 years, a median BASDAI of $51 / 100$, a mean BASFI of 36/100 and a mean ASDAS-CRP score of 2.77; 12 $(67 \%)$ were female; $14(78 \%)$ had a history of enthesitis symptoms, $15(83 \%)$ of arthralgia and $6(33 \%)$ of objective arthritis; 6 (33\%) had psoriasis, 2 (11\%) chronic IBD, $4(22 \%)$ a family history of psoriasis and $13(68 \%)$ a good response to NSAID therapy. Finally, $3(16 \%)$ patients had a baseline CRP $>6 \mathrm{mg} / \mathrm{L}, 2(11 \%)$ had spinal (but not at SIJ) inflammation by MRI. Overall, all 18 patients had at least one objective feature of current arthritis, psoriasis, chronic IBD, uveitis and CRP elevation, in addition to IBP: $12(67 \%)$ patients only one feature, $4(22 \%)$ two features and $2(11 \%)$ three features. Four $(22 \%)$ of them were taking DMARDs therapy. When we compared these 18 PDUS+ASAS- patients to the ASAS+ patients, we found significant differences for only three variables: the ASAS+ patients were younger (33 vs 38 years, $\mathrm{p}=0.0019$ ), had a higher ASAS NSAID score (52 vs 31; $\mathrm{p}=0.0003$ ) and fulfilled more often Amor's criteria (91\% vs $65 \%$, $\mathrm{p}=0.0006)$.

\section{DISCUSSION}

We assessed the value of baseline PDUS defined enthesitis at eight predefined sites for classifying axSpA according to ASAS criteria in 402 DESIR cohort patients with recent IBP suggesting axSpA. The specificity of PDUS defined enthesitis alone for classifying patients according to the axSpA ASAS criteria was quite high $(83 \%)$, with a positive predictive value of $69 \%$. However, sensitivity was only $14 \%$ and the negative predictive value $27 \%$. The prevalence of PDUS defined enthesitis did not differ between patients who did and did not meet ASAS criteria or, within the patients who did meet these criteria, between those who met the clinical criteria and those who met the imaging criteria. Sensitivity and specificity were similar when we used other classification criteria such as the ESSG criteria, Amor's criteria or $\geq 8 / 10$ confidence score in the diagnosis of axSpA assigned by the rheumatologist. A more common history of enthesitis among PDUS+ patients was the only significant difference as compared with PDUSpatients.

In earlier studies, the prevalence of PDUS enthesitis varied widely from $0 \%$ at the Achilles tendon, ${ }^{23}$ in 16 patients meeting axial and peripheral ASAS criteria for $\mathrm{SpA}$ and having a symptom duration of 10 years, $6 \%$ in 36 patients, ${ }^{24}$ meeting modified New York criteria for SpA, 47\% in 197 patients meeting ESSG or Amor's criteria for $\mathrm{SpA}^{25}$ and $76 \%$ in 118 patients with suspected $\mathrm{SpA}$ among whom 51 were finally diagnosed with SpA based on expert opinion. ${ }^{14}$ Possible sources of these discrepancies include major differences in the patient populations, quality of the ultrasound machine, variations in the definition of enthesitis detected by PDUS, disease duration (which ranged from 2 to 10 years), number of entheses evaluated and, perhaps, experience of the sonographers. In most of the studies, the definition of enthesitis by PDUS consisted of morphological and structural abnormalities on B mode (hypoechogenicity, increased thickness, calcifications, enthesophytes, erosions, bursitis) and a positive power Doppler signal within the tendon indicating vascularisation. In contrast, in our study, enthesitis by PDUS was defined only as a power Doppler signal indicating vascularisation at the bony insertion (within $2 \mathrm{~mm}$ 
Table 5 Main characteristics and spondyloarthritis features in the 18 patients with enthesitis by power Doppler ultrasonography who did not meet ASAS criteria for axSpA

\begin{tabular}{|c|c|c|c|c|c|c|c|c|c|c|c|c|c|}
\hline \multirow{2}{*}{$\begin{array}{l}\text { Age } \\
\text { (DD) in } \\
\text { years } \\
\text { Gender }\end{array}$} & \multirow[b]{2}{*}{$\begin{array}{l}\text { ESSG/ } \\
\text { Amor }\end{array}$} & \multirow{2}{*}{$\begin{array}{l}\text { Total } \\
\text { ASAS } \\
\text { SpA } \\
\text { features }\end{array}$} & \multicolumn{11}{|c|}{ ASAS spondyloarthritis feature } \\
\hline & & & IBP & Arthritis & Enthesitis & Uveitis & Dactylitis & Pso & NSAID & CIBD & $\begin{array}{l}\text { FH of } \\
\text { SpA }\end{array}$ & $\begin{array}{l}\text { HLA- } \\
\text { B27 }\end{array}$ & $\begin{array}{l}\text { CRP } \\
>6 \mathrm{mg} / \mathrm{L}\end{array}$ \\
\hline $\begin{array}{l}32(1.34) \\
M\end{array}$ & $+/+$ & 4 & + & - & + & - & - & - & + & + & - & - & - \\
\hline $\begin{array}{l}25(1.08) \\
F\end{array}$ & $+/+$ & 5 & + & + & + & MD & - & $\mathrm{MD}$ & + & MD & + & - & - \\
\hline $\begin{array}{l}39(3.00) \\
F\end{array}$ & $+/+$ & 4 & + & - & + & MD & - & $\mathrm{MD}$ & + & MD & + & - & - \\
\hline $\begin{array}{l}35(2.58) \\
M\end{array}$ & $+/+$ & 6 & + & - & + & + & - & - & + & - & + & - & + \\
\hline $\begin{array}{l}47(1.61) \\
F\end{array}$ & $+/+$ & 3 & + & MD & + & MD & - & $\mathrm{MD}$ & + & MD & - & - & - \\
\hline $\begin{array}{l}32(2.78) \\
F\end{array}$ & $+/+$ & 3 & + & - & - & - & - & + & + & - & - & - & - \\
\hline $\begin{array}{l}49(0.88) \\
F\end{array}$ & $+/+$ & 6 & + & + & + & - & - & + & + & - & - & - & + \\
\hline $\begin{array}{l}35(1.44) \\
M\end{array}$ & $+/+$ & 5 & + & + & - & - & - & + & + & - & - & - & + \\
\hline $\begin{array}{l}48(1.93) \\
F\end{array}$ & $+/+$ & 5 & + & + & + & MD & - & $\mathrm{MD}$ & + & MD & + & - & MD \\
\hline $\begin{array}{l}39(3.30) \\
F\end{array}$ & $+/+$ & 2 & + & - & + & $\mathrm{MD}$ & - & $\mathrm{MD}$ & - & MD & - & - & - \\
\hline $\begin{array}{l}28(1.33) \\
F\end{array}$ & $+/-$ & 4 & + & + & + & - & - & + & - & - & - & - & - \\
\hline $\begin{array}{l}44(1.40) \\
F\end{array}$ & $+/+$ & 4 & + & + & + & MD & - & $\mathrm{MD}$ & + & MD & - & - & - \\
\hline $\begin{array}{l}26(1.62) \\
F\end{array}$ & $+/-$ & 3 & + & - & + & - & - & + & - & - & - & - & - \\
\hline $\begin{array}{l}45(0.44) \\
M\end{array}$ & $+/ \mathrm{MD}$ & 3 & + & - & + & - & - & - & MD & + & - & - & - \\
\hline $\begin{array}{l}42(2.76) \\
F\end{array}$ & $+/-$ & 3 & + & - & + & MD & - & $\mathrm{MD}$ & + & MD & - & - & - \\
\hline $\begin{array}{l}48(1.42) \\
F\end{array}$ & $+/-$ & 2 & + & MD & + & MD & - & $\mathrm{MD}$ & - & MD & - & - & - \\
\hline $\begin{array}{l}34(2.38) \\
M\end{array}$ & $-1-$ & 3 & + & MD & - & - & - & + & + & - & - & - & - \\
\hline $\begin{array}{l}31(0.41) \\
M\end{array}$ & $-1-$ & 2 & + & MD & - & MD & - & MD & + & MD & - & - & - \\
\hline
\end{tabular}

$M$ for male patients and $F$ for female patients.

ASAS, Assessment of SpondyloArthritis international Society; axSpA, axial spondyloarthritis; CIBD, chronic inflammatory bowel disease; CRP, C reactive protein; DD, disease duration, ESSG, European Spondyloarthropathy Study Group; FH, family history; IBP, inflammatory back pain; MD, missing data; NSAID, non-steroidal anti-inflammatory drug; Pso, psoriasis; SpA, spondyloarthritis.

of the cortex), because this sign has been recognised as the most specific ultrasound abnormality in SpA. ${ }^{12-14}$

Our results indicate that PDUS-defined enthesitis is not frequent in patients with recent IBP, even though structural abnormalities, such as calcifications, erosions, increased thickness of tendon and enthesiophytes, were more frequent (about one out of four patients). ${ }^{15}$ Thus, adding PDUS-defined enthesitis to the ASAS criteria set would result in only very few additional patients being classified as axSpA (18 in our study). However, the likelihood of axSpA in these few patients would be very high: in our study, about two-thirds of these patients met
Amor's criteria and 16 (89\%) ESSG criteria, and they all had at least one strong objective feature of SpA (in addition to IBP). These patients would have been missed by the current axSpA ASAS classification criteria, because of normal SIJ MRI and negative HLA-B27, despite otherwise exhibiting the typical profile of axSpA.

PDUS of the entheses is technically challenging and is not yet widely performed as a diagnostic investigation for SpA. The performance of the equipment, sensitivity of the Doppler and experience of the sonographer are of primary importance for evaluating the vascularisation of small entheseal sites and should be taken into 
consideration when evaluating the potential diagnostic value of PDUS for SpA. ${ }^{14}$ In this study, different machines were used and no reliability exercise was done, this must be taken into consideration when interpreting our results. However, specific training may improve the performance of the sonographers. ${ }^{13}$ All the sonographers who performed PDUS for our study were trained in musculoskeletal sonography and specifically to entheseal PDUS by the sonographer responsible of the DESIR cohort. PDUS was performed only in some centres (where ultrasound machines and trained sonographers were available in 2007) can be seen as a limitation, as they included $57 \%$ of all DESIR cohort patients. As compared with the patients who did not undergo to a PDUS examination, they showed a higher prevalence of radiographic sacroiliitis. However, since the prevalence of PDUS enthesitis was similar in patients with and without sacroiliitis, our results probably may apply to the entire DESIR cohort.

In conclusion, in a cohort of patients with recent IBP suggesting early axSpA, PDUS-defined enthesitis at eight predetermined sites was highly specific for classifying patients as having axSpA according to the ASAS criteria. Thus, PDUS of multiple entheseal sites may assist in the classification of axSpA in patients who have highly suggestive manifestations of SpA but fail to meet axSpA ASAS criteria. Further research, including longitudinal studies of PDUS+ patients, are required for understanding the potential value of this evaluation in the classification of IBP highly suggestive of axSpA.

\section{Author affiliations \\ 'Department of Rheumatology, Hôpital Henri Mondor, APHP, Créteil, France ${ }^{2}$ Department of Rheumatology, Hôpital Ambroise Paré, Boulogne-Billancourt, France ${ }^{3}$ INSERM U1173, Laboratoire d'Excellence INFLAMEX, UFR Simone Veil, Versailles- Saint-Quentin University, Versailles, France \\ ${ }^{4}$ Equipe EA2415: Aide à la décision médicale personnalisée, Université Montpellier I, Languedoc Mutualité Nouvelle Technologie, Montpellier, France \\ ${ }^{5}$ INSERM, CIC 1430, Clinical Investigation Center, Créteil, France \\ ${ }^{6}$ Department of Radiology, Hôpital Henri Mondor, APHP, Créteil, France \\ ${ }^{7}$ Department of Rheumatology, Hôpital Nancy Brabois, Nancy, France \\ ${ }^{8}$ Department of Rheumatology, Paris Descartes University, Hôpital Cochin, Paris, France \\ ${ }^{9}$ Assistance Publique, INSERM U1153, Clinical Epidemiology and Biostatistics, Hôpitaux de Paris, Paris, France \\ ${ }^{10}$ Université Paris Est Créteil, EA 7379 - EpidermE, Créteil, France}

Acknowledgements The DESIR cohort was sponsored by the non-profit public funding agency Département de la Recherche Clinique et du Développement, Assistance Publique-Hôpitaux de Paris. This study was conducted under the umbrella of the French Society of Rheumatology and INSERM (Institut National de la Santé et de la Recherche Médicale). The database is managed by the department of epidemiology and biostatistics (Professor Paul Landais, D.I.M) in Nîmes, France. An unrestricted grant from Pfizer was allocated for the 10-year follow-up of the recruited patients. We are grateful to the regional centres that participated in the study: Professor Maxime Dougados (Paris-Cochin B), Professor André Kahan (Paris-Cochin A), Professor Olivier Meyer and Professor Philippe Dieudé (Paris-Bichat), Professor Pierre Bourgeois and Professor Bruno Fautrel (Paris-La Pitié Salpêtrière), Professor Francis Berenbaum (Paris-Saint Antoine), Professor Pascal Claudepierre (Créteil), Professor Maxime Breban (Boulogne Billancourt), Dr Bernadette Saint-Marcoux (Aulnay-sous-Bois), Professor Philippe Goupille (Tours), Professor Jean-Francis Maillefert (Dijon), Dr Xavier Puéchal, Dr Emmanuel Dernis (Le Mans), Professor Daniel Wendling (Besançon), Professor Bernard Combe (Montpellier), Professor Liana Euller-Ziegler (Nice), Professor Philippe Orcel, Professor Pascal Richette (Paris—Lariboisière), Professor Pierre Lafforgue (Marseille), Dr Patrick Boumier (Amiens), Professor Jean-Michel Ristori, Professor
Martin Soubrier (Clermont-Ferrand), Dr Nadia Mehsen (Bordeaux), Professor Damien Loeuille (Nancy), Professor René-Marc Flipo (Lille), Professor Alain Saraux (Brest), Professor Corinne Miceli (Le Kremlin Bicêtre), Professor Alain Cantagrel (Toulouse) and Professor Olivier Vittecoq (Rouen). We also thank the URC-CIC Paris Centre for coordinating and monitoring the study.

Funding The DESIR cohort is supported by a grant from Pfizer.

Competing interests $\mathrm{PC}$ has received consulting fees, speaking fees and/ or honoraria from Pfizer, Abbvie, Roche-Chugai, Bristol-Myers Squibb, MSD, Janssen, Novartis, Celgene and UCB (less than US\$10 000 each) and has been an investigator for Roche-Chugai, Sanofi Aventis, Abbvie, Pfizer, Celgene, UCB and BMS. MAD'A has received consulting fees and or speaking fees (less than US\$10 000 each) from BMS, Roche-Chugai, Abbvie, MSD, Novartis and Pfizer and she is the $\mathrm{Pl}$ of an academic multicentre clinical study which received a grant from Pfizer. MD has received consulting fees and or speaking fees (less than US\$10 000 each) from BMS, Roche-Chugai, Abbvie, MSD, Novartis and Pfizer and he is the PI of an academic multicentre clinical study which received a grant from Pfizer.

Patient consent Obtained.

Provenance and peer review Not commissioned; externally peer reviewed. Data sharing statement № additional data are available.

Open access This is an Open Access article distributed in accordance with the Creative Commons Attribution Non Commercial (CC BY-NC 4.0) license, which permits others to distribute, remix, adapt, build upon this work non-commercially, and license their derivative works on different terms, provided the original work is properly cited and the use is non-commercial. See: http://creativecommons.org/ licenses/by-nc/4.0/

\section{REFERENCES}

1. Rudwaleit M, Khan MA, Sieper J. The challenge of diagnosis and classification in early ankylosing spondylitis: do we need new criteria? Arthritis Rheum 2005;52:1000-8.

2. Rudwaleit M, Landewé R, van der Heijde $\mathrm{D}$, et al. The development of Assessment of SpondyloArthritis international Society classification criteria for axial spondyloarthritis (part I): classification of paper patients by expert opinion including uncertainty appraisal. Ann Rheum Dis 2009;68:770-6.

3. Rudwaleit $\mathrm{M}$, van der Heijde D, Landewé R, et al. The development of Assessment of SpondyloArthritis international Society classification criteria for axial spondyloarthritis (part II): validation and final selection. Ann Rheum Dis 2009;68:777-83.

4. Moltó A, Paternotte S, Comet D, et al. Performances of the Assessment of SpondyloArthritis International Society axial spondyloarthritis criteria for diagnostic and classification purposes in patients visiting a rheumatologist because of chronic back pain: results from a multicenter, cross-sectional study. Arthritis Care Res 2013;65:1472-81.

5. Cheung PP, Paternotte S, Burki V, et al. Performance of the assessment in Spondyloarthritis International Society classification for axial and peripheral spondyloarthritis in an established clinical cohort: comparison with criteria sets of Amor and the European Spondylarthropathy Study Group. J Rheumatol 2012;39:816-21 .

6. Moltó A, Paternotte S, van der Heijde D, et al. Evaluation of the validity of the different arms of the ASAS set of criteria for axial spondyloarthritis and description of the different imaging abnormalities suggestive of spondyloarthritis: data from the DESIR cohort. Ann Rheum Dis 2015;74:746-51.

7. de Hooge M, van den Berg R, Navarro-Compán V, et al. Patients with chronic back pain of short duration from the SPACE cohort: which MRI structural lesions in the sacroiliac joints and inflammatory and structural lesions in the spine are most specific for axial spondyloarthritis? Ann Rheum Dis 2016;75:1308-14.

8. D'Agostino MA, Said-Nahal R, Hacquard-Bouder C, et al. Assessment of peripheral enthesitis in the spondylarthropathies by ultrasonography combined with power Doppler: a cross-sectional study. Arthritis Rheum 2003;48:523-33.

9. de Miguel E, Cobo T, Muñoz-Fernández S, et al. Validity of enthesis ultrasound assessment in spondyloarthropathy. Ann Rheum Dis 2009;68:169-74.

10. Gandjbakhch F, Terslev L, Joshua F, et al. Ultrasound in the evaluation of enthesitis: status and perspectives. Arthritis Res Ther 2011;13:R188.

11. Terslev L, Naredo E, lagnocco A, et al. Defining enthesitis in spondyloarthritis by ultrasound: results of a Delphi process and of a reliability reading exercise. Arthritis Care Res 2014;66:741-8.

12. Feydy A, Lavie-Brion MC, Gossec L, et al. Comparative study of $\mathrm{MRI}$ and power Doppler ultrasonography of the heel in patients with 
spondyloarthritis with and without heel pain and in controls. Ann Rheum Dis 2012;71:498-503.

13. D'agostino MA, Aegerter P, Jousse-Joulin S, et al. How to evaluate and improve the reliability of power Doppler ultrasonography for assessing enthesitis in spondylarthritis. Arthritis Rheum 2009;61:61-9.

14. D'Agostino MA, Aegerter P, Bechara K, et al. How to diagnose spondyloarthritis early? Accuracy of peripheral enthesitis detection by power Doppler ultrasonography. Ann Rheum Dis 2011;70:1433-40.

15. Ruyssen-Witrand A, Jamard B, Cantagrel A, et al. Relationships between ultrasound enthesitis, disease activity and axial radiographic structural changes in patients with early spondyloarthritis: data from DESIR cohort. RMD Open 2017:3:e000482.

16. Dougados M, d'Agostino MA, Benessiano J, et al. The DESIR cohort: a 10-year follow-up of early inflammatory back pain in France: study design and baseline characteristics of the 708 recruited patients. Joint Bone Spine 2011;78:598-603.

17. Dougados $\mathrm{M}$, Etcheto $\mathrm{A}$, Molto $\mathrm{A}$, et al. Clinical presentation of patients suffering from recent onset chronic inflammatory back pain suggestive of spondyloarthritis: the DESIR cohort. Joint Bone Spine 2015;82:345-51.

18. von Elm E, Altman DG, Egger M, et al. The Strengthening the Reporting of Observational Studies in Epidemiology (STROBE) statement: guidelines for reporting observational studies. Ann Intern Med 2007:147:573-7.

19. van den Berg R, Lenczner G, Feydy A, et al. Agreement between clinical practice and trained central reading in reading of sacroiliac joints on plain pelvic radiographs. Results from the DESIR cohort. Arthritis Rheumatol 2014;66:2403-11.

20. Creemers MC, Franssen MJ, van't Hof MA, et al. Assessment of outcome in ankylosing spondylitis: an extended radiographic scoring system. Ann Rheum Dis 2005;64:127-9.

21. Cicchetti DV, Fleiss JL. Comparison of the null distributions of weighted kappa and the C ordinal statistic. Appl Psychol Meas 1977;1:195-201.

22. Fleiss JL. The design and analysis of clinical experiments (Wiley Classics Library). 1384. New York City, NY: Journal of the American Statistical Association, 1999.

23. Mérot $O$, Guillot $P$, Maugars $Y$, et al. Three-dimensional versus twodimensional ultrasonographic assessment of peripheral enthesitis in spondylarthritis. Clin Rheumatol 2014;33:131-5.

24. Spadaro A, lagnocco A, Perrotta FM, et al. Clinical and ultrasonography assessment of peripheral enthesitis in ankylosing spondylitis. Rheumatology 2011;50:2080-6.

25. Naredo E, Batlle-Gualda E, García-Vivar ML, et al. Power Doppler ultrasonography assessment of entheses in spondyloarthropathies: response to therapy of entheseal abnormalities. J Rheumatol 2010;37:2110-7. 